\title{
Ammonia borane enabled upgrading of biomass derivatives at room temperature
}

\author{
Zhao, Wenfeng; Meier, Sebastian; Yang, Song; Riisager, Anders
}

Published in:

Green Chemistry

Link to article, DOI:

10.1039/DOGC02372H

Publication date:

2020

Document Version

Peer reviewed version

Link back to DTU Orbit

Citation (APA):

Zhao, W., Meier, S., Yang, S., \& Riisager, A. (2020). Ammonia borane enabled upgrading of biomass derivatives at room temperature. Green Chemistry, 22, 5972-5977. https://doi.org/10.1039/D0GC02372H

\section{General rights}

Copyright and moral rights for the publications made accessible in the public portal are retained by the authors and/or other copyright owners and it is a condition of accessing publications that users recognise and abide by the legal requirements associated with these rights.

- Users may download and print one copy of any publication from the public portal for the purpose of private study or research.

- You may not further distribute the material or use it for any profit-making activity or commercial gain

- You may freely distribute the URL identifying the publication in the public portal

If you believe that this document breaches copyright please contact us providing details, and we will remove access to the work immediately and investigate your claim 


\title{
Ammonia borane enabled upgrading of biomass derivatives at room temperature
}

Received 00th January 20xx, Accepted 00th January 20xx

DOI: $10.1039 / x 0 x x 00000 x$

\author{
Wenfeng Zhao, ${ }^{\mathrm{a}, \mathrm{b}}$ Sebastian Meier, ${ }^{* \mathrm{~b}}$ Song Yang, ${ }^{* \mathrm{a}}$ and Anders Riisager ${ }^{* \mathrm{~b}}$
}

Simplifying biomass conversion to valuable products with high efficiency is pivotal for the sustainable development of society. Herein, an efficient catalyst-free system using ammonia borane (AB) as the hydrogen donor is described, which enables controllable reaction selectivity towards four value-added products in excellent yield $(82-100 \%)$ under very mild conditions. In particular, the system is uniquely efficient to produce $\gamma$-valerolactone (GVL) at room temperature. Combined in situ NMR and computational studies elucidated the hydrogen transfer mechanism of $A B$ in methanol, the novel pathway of GVL formation from levulinate in water, and a competitive mechanism between reduction and reductive amination in the same system. Moreover, carbohydrates are converted directly into GVL in good yield, using a one-pot, twostep strategy. Products of a rather broad scope are prepared within a short reaction time of $\mathbf{3 0} \mathbf{~ m i n}$ by using this catalyst-free strategy in methanol at room temperature.

Bio-refinement of abundant biomass to liquid fuels and valuable chemicals is promoted as a sustainable strategy to reduce anthropogenic $\mathrm{CO}_{2}$ emissions. ${ }^{[1]}$ Dedicated efforts have focused on the transformation of lignocellulose-derived raw materials into promising platform molecules, including furan-containing compounds, keto-acids, lactone, lactams, diols, and primary amines. ${ }^{[2]}$ In order to obtain most of the above target chemicals, the elaborate design of a suitable catalyst is indispensable, usually accompanied by the use of relatively harsh reaction conditions. For the future biorefinery, it will be essential to develop energy-saving strategies and simple synthesis methods

\footnotetext{
State Key Laboratory Breeding Base of Green Pesticide \& Agricultural Bioengineering, Key Laboratory of Green Pesticide \& Agricultural Bioengineering Ministry of Education, State-Local Joint Laboratory for Comprehensive Utilization of Biomass, Center for Research \& Development of Fine Chemicals Guizhou University, Guiyang 550025, P. R. China

${ }^{b}$ Centre for Catalysis and Sustainable Chemistry, Department of Chemistry, Technical University of Denmark, Kemitorvet Building 207, DK-2800 Kgs. Lyngby, Denmark

*Correspondence to:: semei@kemi.dtu.dk; jhzx.msm@gmail.com; ar@kemi.dtu.dk Electronic Supplementary Information (ESI) available: [details of any supplementary information available should be included here]. See DOI: 10.1039/x0xx00000x
}

in order to achieve a tunable upgrading of biogenic resources to a broad range of useful molecules.

Among the chemicals derived from biomass, levulinic acid (LA) and its esters are particularly easily accessible as they can be formed directly from lignocellulose-based feedstocks. ${ }^{[3]}$ Levulinic acid and its esters are widely utilized to produce $\gamma$ valerolactone (GVL), a prospective fuel and green solvent. ${ }^{[4]}$ In addition, LA is an intermediate of potential industrial importance in producing various chemicals including 5methyl pyrrolidinone (MPD), which is a good organic solvent, dispersant, and surfactant. ${ }^{[5]}$ A reducing agent such as formic acid, alcohol, hydrogen or hydrosilane is necessary for the conversion of levulinic acid (ester) into GVL and MPD. However, certain shortcomings impede the large-scale application of the above hydrogen sources. For example, the use of formic acid requires materials and catalysts with adequate acid resistance, while the hydrosilane system suffers from high price and the need for post-treatment. ${ }^{[6]}$ The use of alcohol as the hydrogen donor necessitates high reaction temperature, and use of molecular hydrogen suffers from operational challenges and from defiance pertaining to storage safety. ${ }^{[7],[8]}$ Moreover, the use of metal-containing catalysts and the use of excess hydrogen source are often unavoidable in current conversion strategies. Finally, it has remained difficult to control the reaction selectivity towards either reduction or reductive amination of the carbonyl group in the same reaction system. Ammonia borane $\left(\mathrm{H}_{3} \mathrm{~N}-\mathrm{BH}_{3}, \mathrm{AB}\right)$ is an attractive solid hydrogen source with a remarkable fraction of available hydrogen (19.6 wt\%) besides being water-soluble, nontoxic, and stable. ${ }^{[9],[10]}$ The $A B$ molecule is highly polar and is capable of selectively reducing imines to amines, ${ }^{[11]} \alpha, \beta$-unsaturated aldehydes to $\alpha$, $\beta$-unsaturated alcohols, ${ }^{[12]}$ and aldehydes or ketones to alcohols ${ }^{[13]}$ by transfer hydrogenation under very mild reaction conditions. In light of these previous findings, we hypothesized that $A B$ should be a clean hydrogen source with attractive selectivity and activity for the reductive conversion of biomassderived compounds. Hence, the current study introduces a versatile catalyst-free reaction system, composed of $A B$ as the 
hydrogen source in a protic solvent. This system allows controllable conversion of biomass-derived levulinic acid (ester) into value-added compounds such as 4-hydroxypentanoic acid or esters, 4-aminopentanoic acid (APA), GVL, and MPD in excellent yields (Scheme 1) under unprecedentedly mild reaction conditions with a tunable selectivity towards the four individual products by appropriate optimization of the reaction conditions. As far as we are aware, this is the first time that $A B$ utilization is described for the reductive conversion of carbohydrate-derived keto-acids to value-added compounds.

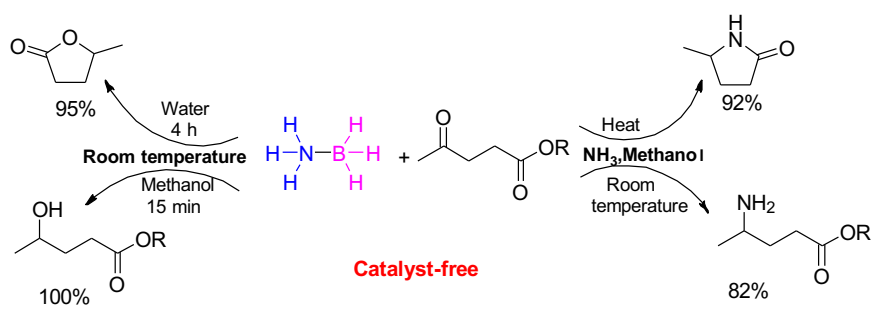

Scheme 1 Reductive conversion of biomass keto-acid into lactam and lactone using a system proposed herein.

Optionally, a variety of carbohydrates can be directly converted into GVL in a one-pot, two-step strategy with a first step employing commercial solid acid catalysts. A broad reaction scope was validated for the $A B$ system by producing various alcohols in neat methanol at room temperature. Moreover, density functional theory (DFT) calculation and in-situ NMR were used to elucidate the reaction mechanism.

\section{Results and discussion}

In a first set of experiments, the upgrading of ethyl levulinate (EL) to GVL was investigated using $A B$ as the hydrogen donor in water at room temperature (rt). Reaction parameters such as reaction time (Figure 1 ) and $A B$ dosage (Figure $S 1$ ) allowed the GVL yield to improve from 57 to $95 \%$ when increasing the reaction time from 0.5 to $4 \mathrm{~h}$, while prolonged reaction time decreased the yield due to GVL hydrolysis into 4hydroxypentanoic acid (HPA) (Figure S2 and Scheme 2). The optimal reaction conditions yielded $95 \% \mathrm{GVL}$ at room temperature ( 1 equiv. $A B, 4 \mathrm{~h}$ ). To the best of our knowledge, this is the most benign system reported for GVL synthesis and a first example demonstrating the catalyst-free synthesis of GVL in water.

Additionally, the water solvent allowed simplified isolation of the GVL by extraction with ethyl acetate (Figure S3). The use of organic solvent instead of water resulted under else identical reaction conditions in no or low GVL yield, but facilitated quantitative formation of ethyl 4-hydroxypentanoate (HPT) (Table S1, Entry 1-5). Especially, methanol (MeOH) resulted in quantitative HPT formation in only 15 min (Entry 6), while heating of the reaction systems with alcoholic solvent was needed for high yields of GVL to be obtained (Figure S4 and Table S2). This observation is consistent with the fact that the formation of a five-membered lactone ring is entropically favored. ${ }^{[14]}$ Accordingly, water may be used as a green solvent for the selective synthesis of GVL, while the more volatile methanol can be used as solvent for production of the corresponding alcohol HPT.

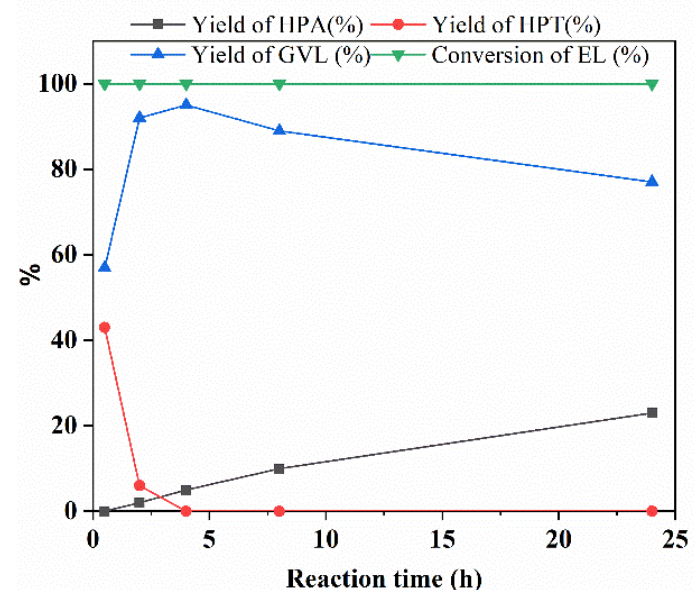

Figure 1. Conversion of ethyl levulinate in water over time. Reaction conditions: $1 \mathrm{mmol} E L, 1 \mathrm{mmol} A B, 2 \mathrm{~mL}$ water, and room temperature

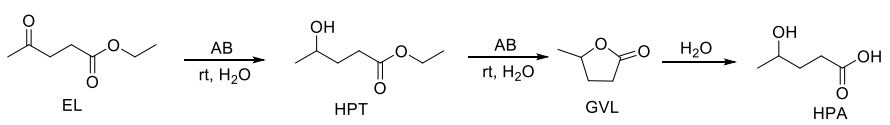

Scheme 2. The conversion pathway of EL in water.

The $A B$ system was also evaluated with $L A$ as the substrate, but here GVL was not obtained neither in water nor in $\mathrm{MeOH}$ at room temperature opposite to EL. Instead, HPA formed as the dominating product. This suggested that the carboxylic acid group of LA altered the reaction pathway and prevented the cyclization of HPA, instead of resulting in easy lactonization from the HPT ester intermediate. ${ }^{[15]}$ Besides HPA, a nonnegligible amount of APA product was also found after reaction in neat $\mathrm{MeOH}$ solvent at room temperature (Figure S5). Likewise, MPD formed upon heating thus demonstrating that $A B$ decomposed to ammonia and aminated the keto group in LA.

The serendipitous observation of LA amination stimulated subsequent attempts to introduce additional ammonia sources into the system to enhance the yield of APA and MPD, including various ammonium compounds and solvent-dissolved ammonia (Figure S6 and Table S3). The results demonstrated that ammonium carbonate and ammonium acetate led to high MPD yields of $50-70 \%$ in methanol (Table S3, Entries 1 and 2), while methanolic ammonia was an even better ammonia source affording a yield of $74 \%$ of MPD (Table S3, Entry 5). Reaction time and temperature were further optimized with methanolic ammonia (16 wt.\%), and resulted in an MPD yield of 92\% after $12 \mathrm{~h}$ of reaction at $120^{\circ} \mathrm{C}$ (Table S3, Entry 10 ) and an APA yield of $82 \%$ after $2 \mathrm{~h}$ of reaction at room temperature (Table S3, Entry 13). The influence of ammonia content in methanol on MPD selectivity was further evaluated (Figure 2). The evaluation illustrated that the selectivity towards MPD improved with increasing ammonia content (maximum with 12-16 wt.\% ammonia), implying that the ammonia addition resulted in higher yields of MPD at the expense of GVL and HPA. Hence, the 
use of $A B$ as hydrogen source overall afforded (1) formation of HPT with a yield near $100 \%$ in methanol at room temperature, (2) formation of GVL with an excellent yield of $95 \%$ in water at room temperature, (3) formation of APA with a yield of $82 \%$ at room temperature, and (4) formation of MPD with a yield of $92 \%$ at $120^{\circ} \mathrm{C}$.

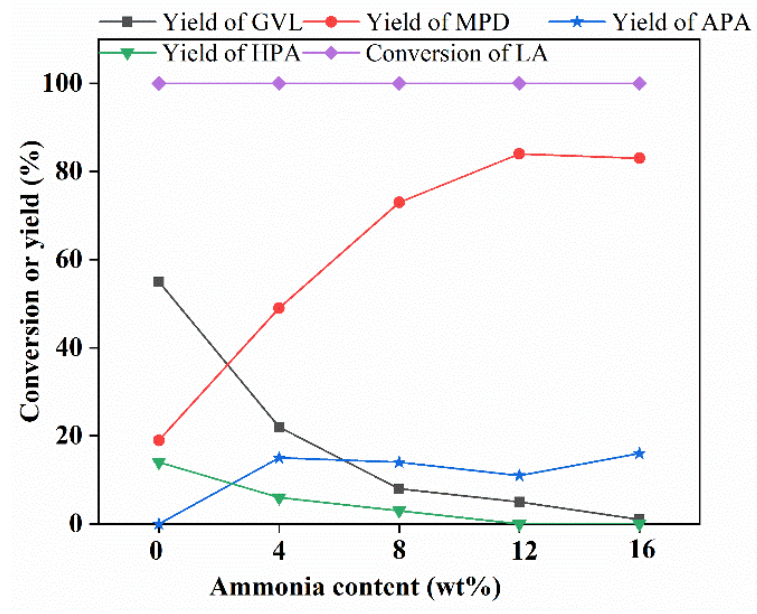

Figure 2. The effect of ammonia content on the production of MPD. Reaction conditions: $1 \mathrm{mmol} \mathrm{LA}, 1 \mathrm{mmol} \mathrm{AB}, 4 \mathrm{~mL} \mathrm{MeOH}$ containing ammonia, $120^{\circ} \mathrm{C}$, and $4 \mathrm{~h}$

The remarkably efficient formation of GVL from EL using $A B$ as hydrogen-donor in water prompted us to study the corresponding reaction mechanism. Previous investigations have validated that the $A B$ hydrolysis product in water is boric acid and the alcoholysis product in methanol is trimethyl borate (Scheme S2). ${ }^{[16]}$ Thus, one could hypothesize that boric acid might be able to promote the cyclization of HPT. To evaluate this hypothesis, HPT was used as reactant to produce GVL with boric acid rather than $A B$ in water and methanol (Scheme S3). The results revealed no GVL formation in methanol nor in water, demonstrating that boric acid was not promoting the cyclization of HPT to GVL. Instead, based on the obtained data from the formation of GVL from EL in water, and consistent with previous studies, ${ }^{[11,17]}$ we propose a novel, plausible reaction mechanism for the GVL formation using $A B$ as a hydrogen donor (Scheme 3). In this mechanism, borane (or diborane) generated by hydrolysis of $A B$ initially forms the intermediate Int-1 by hydroboration of EL. Subsequently, Int-1 react with LA to generate Int-2, which in water quickly converts into GVL through hydrolytic cyclization with co-formation of boric acid and ethanol.

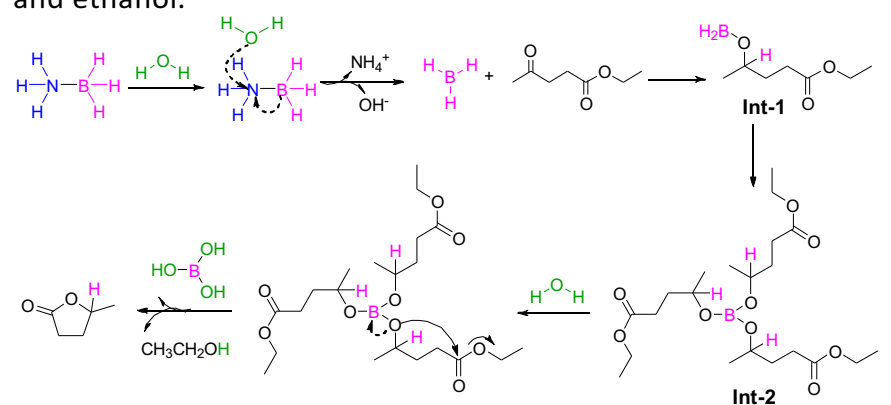

Scheme 3. Novel plausible reaction mechanism for formation of $G V L$ in water with $A B$ as the hydrogen source.

To corroborate the proposed mechanism, in situ NMR spectroscopy was applied to monitor the conversion of $E L$ in water by acquiring a series of $1 D$ NMR spectra in a pseudo-2D manner. The in situ ${ }^{13} \mathrm{C}$ NMR spectra of the GVL formation in water (Figure 3a) confirmed that EL was almost completely consumed within $15 \mathrm{~min}$ and that GVL was generated from intermediates, including HPT and derivatized HPT formed in situ. The ${ }^{1} \mathrm{H}^{13} \mathrm{C}$ HSQC spectra (Figure 3c) of the conversion of EL in water showed the presence of both borate ester (Int-2) and HPT intermediates. The in situ ${ }^{13} \mathrm{C}$ NMR spectra with HPT as the substrate under identical reaction conditions (Figures $3 \mathrm{~b}$ and $3 d$ ) also revealed that HPT was converted slower into GVL than $\mathrm{EL}$ as substrate. Thus, HPT required a longer reaction time (20 h) than EL to reach full conversion, indicating that HPT may not be the dominating intermediate during the formation of GVL. Moreover, in situ ${ }^{11} \mathrm{~B} N \mathrm{NMR}$ spectroscopy of $\mathrm{EL}$ conversion to GVL in water detected the formation of boric acid $(11.0 \mathrm{ppm})^{[18]}$ from $A B$ (Figure S7). These spectroscopic results are consistent with the proposed reaction pathway shown in Scheme 3 for the production of GVL in water at room temperature. To compare the product distribution in different solvents, in situ ${ }^{13} \mathrm{C} N M R$ spectroscopy of EL hydrogenation was performed in methanol (Figure S8). Here, HPT was observed as the only main product whereas no GVL was found. Obviously, water and methanol as polar solvents enable EL to form HPT and borate ester in the presence of $A B$, while only the water system shows unique reactivity toward the production of $\mathrm{GVL}$, while methanol cannot promote cyclization of borate ester into GVL. However, GVL was accessible when adding water into the methanolic reaction mixture affording $80 \%$ yield at room temperature (Scheme 54 ), which further illustrated that water played a key role in the hydrolysis of Int-2 and the production of GVL.

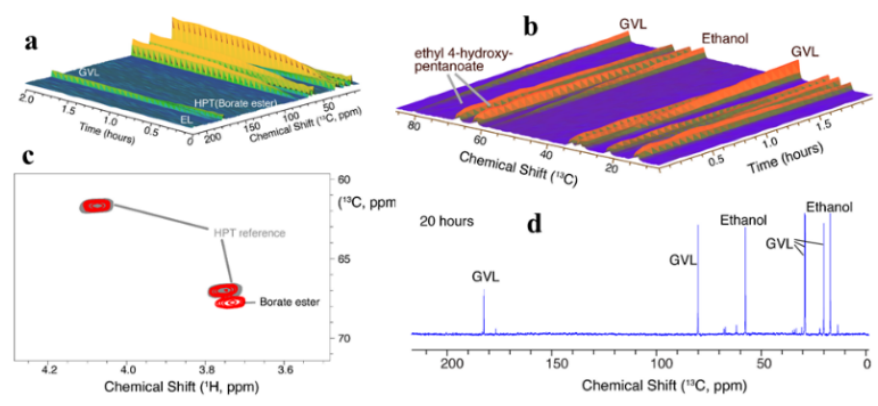

Figure 3. In situ NMR spectroscopic observations consistent with the reaction mechanism proosed in Scheme 3. a) In situ ${ }^{13} \mathrm{C}$ NMR spectroscopy of GVL formation from EL via HPT and borate ester Int-2 in water $(0.5 \mathrm{mmol} \mathrm{EL}, 1 \mathrm{~mL}$ water, $0.5 \mathrm{mmol} A B$, and room temperature). b) In situ ${ }^{13} \mathrm{C} N \mathrm{NMR}$ of GVL production from HPT in water $(0.5 \mathrm{mmol} \mathrm{HPT,} 1 \mathrm{~mL}$ water, $0.5 \mathrm{mmol}$ ammonia borane, and room temperature). c) ${ }^{1} \mathrm{H}_{-}{ }^{13} \mathrm{C}$ HSQC spectra of postreaction mixture from a). d) ${ }^{13} \mathrm{C}$ NMR spectra of post-reaction mixture from $b$ ). 
As detailed above, the hydrogenation of LA and its ester in methanol exhibited high selectivity towards HPA or the corresponding ester, while reductive amination could be achieved when conducting the reaction in methanol containing 16 wt.\% ammonia. Consistent with the reactivity of $A B$ in methanol, ${ }^{[11,18 b, 19]}$ four possible reaction pathways were considered for the production of MPD and GVL, as shown in Scheme 4 . The mechanism contains two ambiguous points, as (1) the mode of $A B$ action could be based either on singlehydrogen-transfer (SHT) or on double-hydrogen-transfer (DHT), and (2) the competition between reduction of the carbonyl group and reductive amination remained unclear.

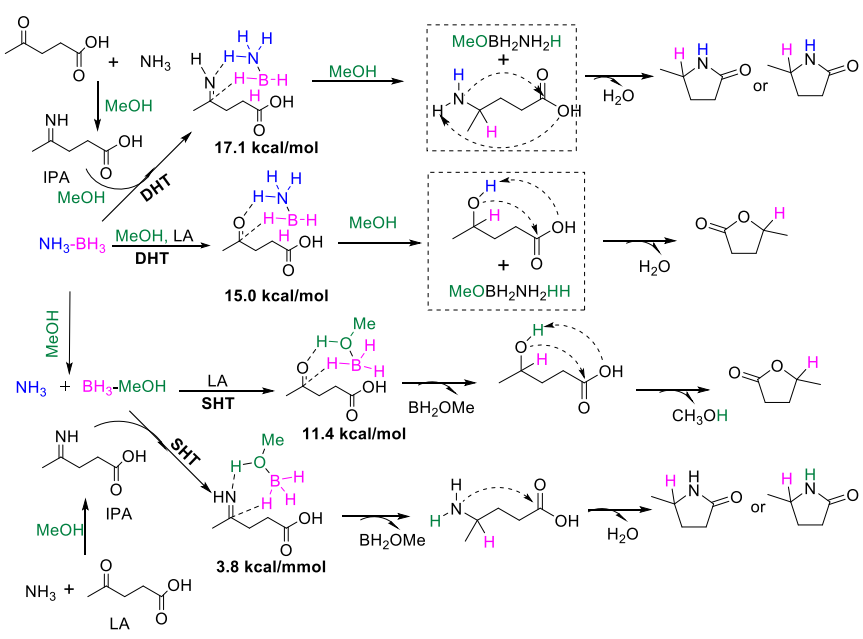

Scheme 4. Possible reaction mechanisms for the conversion of LA into GVL and MPD in methanol based on single-hydrogentransfer (SHT) or double-hydrogen-transfer (DHT).

Density functional theory (DFT) calculations were implemented to determine the variation of free energies of all intermediates and products involved in the four pathways. Scheme S5a displays the resulting energy profiles of formation of HPA upon hydrogenation of LA promoted through two conceivable different functions of $A B$. $A B$ interacts with $L A$ to form ts 5 during the DHT pathway, and the methanol borane complex $\left(\mathrm{CH}_{3} \mathrm{OHBH}_{3}\right)$, generated from decomposed $\mathrm{AB}$, approaches $\mathrm{LA}$ to afford ts3 during the SHT pathway. The calculations established that ts 3 has lower free energy $(11.4 \mathrm{kcal} / \mathrm{mol})$ than ts5 $(15.0 \mathrm{kcal} / \mathrm{mol})$. Alternatively, the energy profiles of APA formation via the hydrogenation of the imine intermediate 4iminopentanoic acid (IPA) through two different modes of $A B$ action are displayed in Scheme S5b. These energy profiles indicate that the transition state $\mathbf{t s} 4(3.8 \mathrm{kcal} / \mathrm{mol})$ produced from decomposed $A B$ is more accessible than ts6 (17 $\mathrm{kcal} / \mathrm{mmol}$ ) produced from unbroken AB. Theoretically, the SHT pathway is thus more favorable than DHT both in the reduction of the carbonyl group and of the imine functionality. Furthermore, some APA was experimentally detected in the absence of added ammonia (Figure S5), further illustrating the tendency of $A B$ to decompose into free ammonia and borane rather than acting in the intact $A B$ molecular form.
To further support the DFT calculations, deuterium labeling experiments were conducted using deuterated $A B$ isotopologues including $\mathrm{NH}_{3} \mathrm{BD}_{3}(\mathrm{AB}(\mathrm{D})), \mathrm{ND}_{3} \mathrm{BH}_{3}(\mathrm{~A}(\mathrm{D}) \mathrm{B})$, and $N_{3} B D_{3}(A(D) B(D))$ to convert $L A$ into GVL and MPD. As shown in Figure S9-S14, MPD was generated with high fractions of 100 amu $\mathrm{m} / \mathrm{z}$ and 101 amu $\mathrm{m} / \mathrm{z}$ when employing $A B(D)$ as the reductant in normal and deuterated methanol, respectively, while only product with 99 amu $\mathrm{m} / \mathrm{z}$ was afforded with $A(D) B$ or $A B$ as the reductant. Additionally, the ${ }^{1} H$ NMR spectra of GVL formed by using $A B(D)$ showed the loss of coupling in the methyl group with chemical shift of $1.4 \mathrm{ppm}$, and the disappearance of the characteristic signal at $4.5 \mathrm{ppm}$ upon incorporation of a deuterium during carbonyl reduction (Figure S15). This observation confirms that the two protons of MPD derived from borane and alcohol groups, rather than from the nitrogen part of the $A B$ molecules. Accordingly, these results unambiguously showed that the predominant conversion route followed the SHT mechanism.

In the SHT mechanism, the free energy of ts $3(11.4 \mathrm{kcal} / \mathrm{mol})$ in the reduction of the carbonyl group of LA is higher compared to the free energy of ts $4(3.8 \mathrm{kcal} / \mathrm{mol})$ in the reduction of the imine group of IPA, implying that the latter reduction is more likely. However, the amination of LA to IPA passes transition states ts1 $(37.0 \mathrm{kcal} / \mathrm{mol})$ and ts2 $(59.1 \mathrm{kcal} / \mathrm{mol})$ with highenergy barriers (Scheme S6) in the production of APA. Thus, the hydrogenation of LA to HPA is more favorable than the reductive amination of LA to APA, owing to the high free energy of ts1 and ts2 during the formation of IPA. Nevertheless, previous reports and our experimental findings show that the reductive amination was expedited by increasing ammonia dosage. ${ }^{[15 a]}$ Thus, the selectivity of MPD increased with the ammonia content and reached quantitative conversion to MPD when using approximately 26 equiv. ammonia (see Figure 2 ). In situ ${ }^{13} \mathrm{C}$ NMR studies of the conversion of LA into HPA and APA were used to probe the theoretically predicted reaction pathway by monitoring product distributions (Figure 4). It is unambiguous that APA was the dominant product in the presence of a surplus of ammonia (Figure 4a), and HPA was the primary product in the absence of added ammonia (Figure $4 \mathrm{~b}$ ). These results illustrate that the reduction of LA was a dominant reaction pathway in the conversion of $L A$ using the $A B$-methanol system, while reaction selectivity toward reductive amination could be realized using the AB-methanol system with added ammonia.
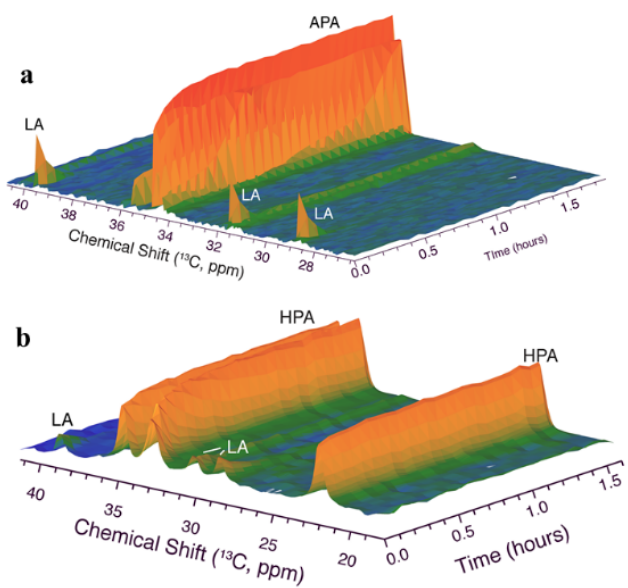
Figure 4. In situ ${ }^{13} \mathrm{C}$ NMR spectroscopy of (a) LA conversion in the formation of APA $(0.5 \mathrm{mmol} L A, 0.5 \mathrm{mmol} \mathrm{AB}, 1 \mathrm{~mL}$ methanol containing $16 \mathrm{wt} . \%$ ammonia, room temperature, and $2 \mathrm{~h}$ ), and in the formation of (b) HPA from LA ( $0.5 \mathrm{mmol}$ LA, 0.5 $\mathrm{mmol} A B, 1 \mathrm{~mL}$ methanol, room temperature, and $2 \mathrm{~h}$ ).

Since levulinate esters can be obtained rather swiftly from carbohydrates by acid catalysis in alcohols, ${ }^{[20]}$ a series of saccharides was directly employed as feedstock for the production of GVL using a two-step protocol. In a first reaction step, methyl levulinate was produced from fructose-based substrates over Amberlyst-15 in $\mathrm{MeOH}$ (Table 1, Entries 1-3) and from glucose-based substrates over a mixture of Amberlyst15 and Sn-beta (Si/Sn ratio of 125 ) catalyst (Table 1, Entries 46). After the first step, $A B$ and water were directly added into the resulting reaction mixture without any prior sample workup and the reaction allowed to proceed for another $8 \mathrm{~h}$ at room temperature. This procedure resulted in the formation of GVL at a yield of $60 \%$ from fructose and of $51 \%$ from glucose, while attractive results were achieved from the other carbohydrate substrates as well. Thus, the results demonstrated that implementation of the $A B$ system provides an efficient strategy for the direct conversion of biomass-derived carbohydrates into valuable GVL.

Table 1. Direct production of GVL from biomass saccharides. ${ }^{[a]}$

\begin{tabular}{ccccc}
\hline Entry & Sugar & $\begin{array}{c}\text { Yield GVL } \\
(\%)\end{array}$ & $\begin{array}{c}\text { Yield HPA } \\
(\%)\end{array}$ & $\begin{array}{c}\text { Conversion } \\
(\%)\end{array}$ \\
\hline 1 & Fructose & 60 & 9 & $>99$ \\
2 & Sucrose & 35 & 11 & $>99$ \\
3 & Inulin & 22 & 8 & $>99$ \\
$4^{[\mathrm{b}]}$ & Glucose & 51 & 10 & $>99$ \\
$5^{[\mathrm{b}]}$ & Cellobiose & 40 & 6 & $>99$ \\
$6^{[\mathrm{b}]}$ & Mannose & 45 & 6 & $>99$ \\
\hline
\end{tabular}

[a] Reaction conditions: $180 \mathrm{mg}$ sugar, $100 \mathrm{mg}$ Amberlyst-15, $4.0 \mathrm{~g}$ methanol, $30 \mathrm{mg} \mathrm{AB}$ and $5.0 \mathrm{~g}$ water; First step at $160 \mathrm{\circ} \mathrm{C}$ for $5 \mathrm{~h}$ and second step after addition of $5 \mathrm{~mL}$ water and $30 \mathrm{mg}$ $A B$ for room temperature and $8 \mathrm{~h}$. [b] Except for adding $50 \mathrm{mg}$ Sn-beta (125), all other conditions were similar to [a]. Yields were quantified by ${ }^{1} \mathrm{H}$ NMR spectroscopy using DMF as an internal standard.

Finally, the reaction scope of the AB system was evaluated using other biomass-derived aldehydes and ketones as substrates (Table 2). Remarkably, the system exhibited good to excellent activity for conversion of the compounds into the corresponding alcohols using $\mathrm{MeOH}$ as solvent under very mild conditions of room temperature and $30 \mathrm{~min}$ reaction time. Substrates included levulinate esters with different chain lengths, aliphatic/aromatic aldehydes and ketones, $\alpha, \beta$ unsaturated aldehydes, and various furanics. Notably, aldehydes showed higher reactivity than ketones (comparison of $\mathbf{1 2 b}$ and $\mathbf{1 5 b}$ ), and some substrates containing electronwithdrawing groups at the aryl ring displayed faster reactions than substrates with an electron-donating group, such as $\mathbf{1 1 b}$, 14b, and 17b. However, the majority of substrates showed comparable, quantitative conversion, likely because the reaction system operated too quickly to observe the differences between substrates with electron-donating or electronwithdrawing substituents.

Table 2. Formation of alcohols from biomass-derived aldehydes and ketones. ${ }^{[a]}$

(1)

[a] Reaction conditions: $1 \mathrm{mmol}$ substrate, $1 \mathrm{mmol} A B, 2 \mathrm{~mL}$ $\mathrm{MeOH}, 30 \mathrm{~min}$, and room temperature. Yields are indicated in parenthesis and were quantified with ${ }^{1} \mathrm{H}$ NMR using mesitylene as internal standard.

\section{Conclusions}

In conclusion, an energy-saving and efficient catalyst-free strategy to selectively convert biomass-derived aldehydes and ketones into HPA (or ester), APA, GVL or MPD in excellent yields has been established using $A B$ as the hydrogen donor under mild reaction conditions. Interestingly, the solvent directed the reaction selectivity towards alcohol or GVL, and ammonia contents in the reaction mixture promoted the selectivity toward reduction or reductive amination of the carbonyl groups. Thus, for the first time, a remarkable yield of GVL of up to $95 \%$ was obtained in water at room temperature without any post-processing operation. In situ NMR illustrated that the reaction pathway forming GVL from levulinate in water encompassed hydrolytic cyclization of an intermediate borate ester. Likewise, in situ NMR and computational studies elucidated the mechanism of $A B$ action and the competitive mechanism between the reduction and reductive amination of the carbonyl groups in the same reaction system. Additionally, carbohydrates and heterogeneous catalysts were employed to 
directly produce GVL with a two-step strategy, affording a GVL yield of $51 \%$ from glucose. Finally, a wide substrate scope was demonstrated for the reaction system with the conversion of various ketones and aldehydes into the corresponding alcohols in excellent yield at room temperature. The introduced system with $A B$ as a reducing agent is arguably among the most efficient, simple, environmentally friendly, and energy-saving systems developed to date for the selective reductive conversion of biomass-derived compounds. Accordingly, it can be anticipated the results will open significant new possibilities for the reductive conversion of biomass.

\section{Conflicts of interest}

The authors declare no competing interests.

\section{Acknowledgements}

WZ acknowledge The Chinese State Scholarship (No. 201906670009) for supporting a stay at the Technical University of Denmark to conduct this study. SY acknowledges the National Natural Science Foundation of China (No. 21576059 and 21666008), while AR and SM acknowledge the Department of Chemistry, Technical University of Denmark for support. 800 $\mathrm{MHz}$ NMR spectra were recorded on the spectrometer of the DTU NMR Center supported by the Villum Foundation.

\section{Notes and references}

1 Y. Liao, S. F. Koelewijn, G. Van den Bossche, J. Van Aelst, S. Van den Bosch, T. Renders, , K. Navare, T. Nicolaï, K. Van Aelst, M. Maesen, H. Matsushima, J. Thevelein, K. Van Acker, B. Lagrain, D. Verboekend, B. F. Sels, Science 2020, 367, 1385-1390.

2 a) C. Li, L. Wang, M. Wang, B. Liu, X. Liu, D. Cu, Angew. Chem. 2019, 131, 11556-11560. b) Á. Szabolcs, M. Molnár, G. Dibó, Green Chem. 2013, 15, 439-445. c) S. Li, Y. Wang, Y. Yang, B. Chen, J. Tai, H. Liu, B. Han, Green Chem. 2019, 21, 770-774. d) C. Xie, J. Song, H. Wu, Y. Hu, H. Liu, Z. Zhang, P. Zhang, B. F. Chen, B. Han, J. Am. Chem. Soc. 2019, 141, 4002-4009. e) F. M. A. Geilen, B. Engendahl, A. Harwardt, W. Marquardt, J. Klankermayer, W. Leitner, Angew. Chem. Int. Ed. 2010, 49, 5510-5514. f) T. Komanoya, T. Kinemura, Y. Kita, K. Kamata, M. Hara, J. Am. Chem. Soc. 2017, 139, 11493-11499.

3 a) M. Mascal, E. B. Nikitin, Green Chem. 2010, 12, 370-373. b) S. Kang, J. Fu, G. Zhang, Renew. Sust. Energ. Rev. 2018, 94, 340-362

4 a) K. Yan, Y. Yang, J. Chai, Y. Lu, Appl. Catal. B: Environ. 2015, 179, 292-304. b) S. G. Wettstein, D. M. Alonso, Y. Chong, J. A. Dumesic, Energ. Environ. Sci. 2012, 5, 8199-8203.

5 a) A. S. Touchy, S. M. A. Hakim Siddiki, K. Kon, K. I. Shimizu, ACS Catal. 2014, 4, 3045-3050. b) W. Luo, M. Sankar, A. M. Beale, Q. He, C. J. Kiely, P. C. Bruijnincx, B. M. Weckhuysen, Nature Commun. 2015, 6, 1-10.

6 H. Li, W. Zhao, W. Dai, J. Long, M. Watanabe, S. Meier, S. Saravanamurugan. S. Yang, A. Riisager, Green Chem. 2018, 20, 5327-5335.

7 a) X. L. Du, L. He, S. Zhao, Y. M. Liu, Y. Cao, H. Y. He, K. N. Fan, Angew. Chem. Int. Ed. 2011, 50, 7815-7819. b) L. Deng, Y.
Zhao, J. Li, Y. Fu, B. Liao, Q. X. Guo, ChemSusChem 2010, 3, 1172-1175. c) W. Zhao, T. Yang, H. Li, W. Wu, Z. Wang, C. Fang, S. Saravanamurugan, S. Yang, ACS Sustain. Chem. Eng. 2017, 5, 9640-9644. d) J. He, H. Li, A. Riisager, S. Yang, Chem CatChem 2018, 10, 430-438. d) Z. Liu, Z. Yang, P. Wang, X. Yu, Y. Wu, H. Wang, Z. Liu, ACS Sustain. Chem. Eng. 2019, 7, 18236-18241.

8 a) H. Li, H. Wu, H. Zhang, Y. Su, S. Yang, E. J. Hensen, ChemSusChem 2019, 12, 3778-3784. b) C. Wu, X. Luo, H. Zhang, X. Liu, G. Ji, Z. Liu, Z. Liu, Green Chem. 2017, 19, 3525-3529. c) A. S. Touchy, S. M. A. Hakim Siddiki, K. Kon, K. I. Shimizu, ACS Catal. 2014, 4, 3045-3050.

9 a) B. Peng, J. Chen, Energ. Environ. Sci. 2008, 1, 479-483. b) V. Rizzi, D. Polino, E. Sicilia, N. Russo, M. Parrinello, Angew. Chem. Int. Ed. 2019, 58, 3976-3980.

10 M. E. Bluhm, M. G. Bradley, R. Butterick, U. Kusari, L. G. Sneddon, J. Am. Chem. Soc. 2006, 128, 7748-7749.

11 X. Yang, L. Zhao, T. Fox, Z. X. Wang, H. Berke, Angew. Chem. Int. Ed. 2010, 49, 2058-2062.

12 Y. Zhou, Z. Li, Y. Liu, J. Huo, C. Chen, Q. Li, S. Y. Niu, S. Wang, ChemSusChem 2020, 13, 1746-1750.

13 L. Shi, Y. Liu, Q. Liu, B. Wei, G. Zhang, Green Chem. 2012, 14, 1372-1375.

14 a) F. C. Lightstone, T. C. Bruice, Bioorg. Chem. 1998, 26, 193199. b) G. Illuminati, L. Mandolini, Accounts Chem. Res. 1981, 14, 95-102.

15 a) A. Pelter, R. M. Rosser, S. Mills, J. Chem. Soc. Perkin Trans. 1984, 1, 717-720. b) H. C. Kelly, V. B. Marriott, Inorg. Chem. 1979, 18, 2875-2878.

16 a) X. Yang, T. Fox, H. Berke, Tetrahedron 2011, 67, 7121-7127. b) J. S. Wang, R. A. Geanangel, Inorg. Chim. Acta 1988, 148, 185-190.

17 C. Adams, V. Gold, D. M. Reuben, J. Chem. Soc. Perk. Trans. 1977, 2, 1466-1472.

18 a) D. C. Wigfield, F. W. Gowland, Tetrahedron Lett. 1976, 17, 3373-3376; b) I. E. Golub, E. S. Gulyaeva, O. A. Filippov, V. P. Dyadchenko, N. V. Belkova, L. M. Epstein, E. S. Shubina, J. Phys. Chem. A 2015, 119, 3853-3868.

19 X. Wang, W. Yao, D. Zhou, H. Fan, Mol. Phys. 2013, 111, 3014 3024.

20 a) L. Peng, L. Lin, H. Li, Q. Yang, Appl. Energ. 2011, 88, 45904596. b) L. Jiang, L. Zhou, J. Chao, H. Zhao, T. Lu, Y. Su, X. M. Yang, J. Xu, Appl. Catal. B: Environ. 2018, 220, 589-596. 